\section{The Neolithic origins of seafaring in the Arabian Gulf Robert Carter}

The inhabitants of the Arabian Gulf were among the world's earliest maritime traders. Their ships sailed regularly between the Bronze Age civilizations of Mesopotamia, Bahrain and the Indus Valley, and they reached China by sea in the eighth century $A D$, thus bypassing the long and perilous overland Silk Road route across Central Asia. Now excavations at a coastal site in Kuwait by a team from the Institute have revealed even earlier evidence of maritime activity in the Gulf.

I

nvestigations in Kuwait by our team from the Institute ${ }^{1}$ have revealed that maritime trade began as early as the sixth millennium BC. The coastal site we have excavated has yielded fragments of the waterproof coating that covered seagoing vessels made of bundles of reeds. These fragments consist of bitumen slabs with reed impressions on one side and barnacles on the other. Other finds from the site include imported goods, a pottery model of a reed-bundle boat, and what appears to be a depiction of a sailing vessel - all testifying to the importance of maritime trade.

\section{Existing evidence for trade}

These new finds in Kuwait complement prior knowledge of a phase of interaction between southern Mesopotamia and the Arabian Gulf. Archaeologists have long speculated about a distinctive type of Mesopotamian pottery found in the Arabian Gulf region, known as Ubaid ware, which dates to the sixth and fifth millennia $\mathrm{BC}^{2}$ and was made by the earliest known farming communities of southern Mesopotamia, now in Iraq. Some Ubaid settlements later became the mighty cities of the Sumerian civilization, such as Ur, Uruk and Eridu (Fig. 1), but during the Ubaid period city life and writing had not yet been developed, and settlements remained relatively small, sustained by agriculture, livestock herding and fishing.

The Ubaid pottery found at sites in the Arabian Gulf has travelled far beyond its area of origin. ${ }^{3}$ Most of the relevant sites are coastal and are located in eastern Saudi Arabia, Qatar and the island of Bahrain (the Central Gulf region; Fig. 1). In recent years, sites with Ubaid pottery have been found farther south down the Gulf, in the United Arab Emirates, and about 60 are now known. The most southerly sites are in Ras al-Khaimah, close to the mouth of the Gulf, some $1100 \mathrm{~km}$ from the most southerly Ubaid site in Mesopotamia.

In the Gulf region, Ubaid pottery is associated with sites of the Arabian Neolithic period, which is partially contemporary with the Ubaid period to the north. ${ }^{4}$ In contrast to Mesopotamia, agriculture was not established in the Arabian peninsula at this time, and the local economy relied on the herding of sheep, goats and cattle, as well as on fishing, hunting and gathering. Pottery was not made or used by Arabian Neolithic peoples before the arrival of Ubaid ceramics.

A pattern is evident in the distribution of the Ubaid pottery and related sites in the Gulf. The more easterly sites, including those in Qatar and Bahrain, are comparatively poor in pottery, and the remains found suggest that they were occupied only temporarily or seasonally. The archaeological deposits are usually shallow and consist of accumulations of shells (shell middens), fire pits and fishbones. However, west of Qatar, pottery is more commonly found. As well as ephemeral campsites, there are some larger sites with deep archaeological deposits. These are found at Dosariyah, Abu Khamis, Khursaniyah and Ain Qannas (Fig. 1).

Archaeologists have advanced several hypotheses to explain the spread of Ubaid pottery. One is that Mesopotamian fishermen periodically travelled by sea from southern Iraq, to catch and dry fish in the Arabian Gulf, and perhaps to acquire other goods such as pearls, and flint and obsidian for tool manufacture. ${ }^{5}$ According to this hypothesis, the pottery was not primarily intended for exchange with the local population, but was brought by and for the use of the visitors from Mesopotamia. A very different hypothesis suggests that Ubaid Mesopotamia and eastern Arabia were part of the same regional socioeconomic system, the two areas being bound together by longstanding economic, social and demographic ties, and that the pottery was moved by groups who engaged in regular overland movement between the two areas. ${ }^{6}$ However, the evidence from Kuwait now suggests a new interpretation.

\section{The site}

The site we have excavated in Kuwait resembles the larger ones of the Central Gulf region, although certain Mesopotamian-style artefacts occur there that are absent from the Central Gulf sites. ${ }^{7}$ The site was found by a Kuwaiti archaeologist in the 1980s in an area on the north side of Kuwait Bay called as-Sabiyah and was named H3 by the then Director of the National Museum of Kuwait, Dr Fahad al-Wohaibi. At the time of its Neolithic occupation, it was on a narrow peninsula or long island that enclosed a shallow bay. Since then, thick deposits of mud have partly filled the bay and extended the coastline several kilometres to the south, but in Neolithic times the site was in an area of diverse plant and animal resources and it faced a sheltered anchorage.

Four seasons of fieldwork, carried out between 1998 and 2002, ${ }^{8}$ have shown that H3 began as a campsite with many fire pits, often re-used, located close to or on the beach. In this respect it is typical of other Arabian Neolithic sites. Ubaid pottery was present but rare in this earliest fire-pit phase, which has been dated by radiocarbon to approximately 7500 (calibrated) years ago. Later in the Neolithic period a remarkable change occurred. Stone structures were built, in the form of cellular buildings divided into chambers (Fig. 2). Some of the chambers were used for living and eating, but the function of others remains unknown. Many of them were

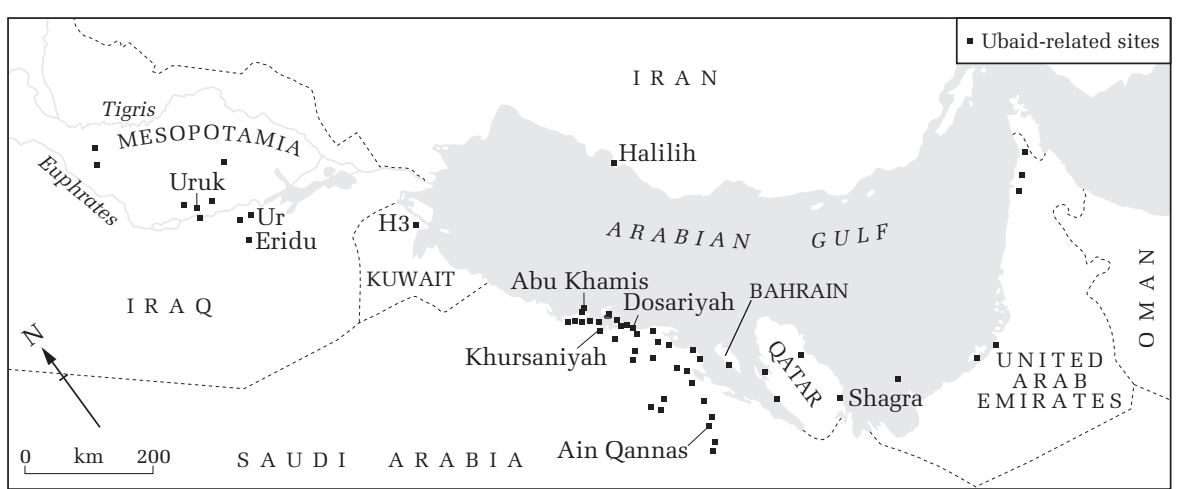

Figure 1 Mesopotamia and the Arabian Gulf, showing the distribution of Ubaid (Mesopotamia) and Neolithic (Gulf) sites of the sixth and fifth millennia BC; only those sites mentioned in the text are named. Lack of systematic archaeological survey probably accounts for the apparent absence of sites in the area north and south of H3 and in coastal Iran. H3 is over $250 \mathrm{~km}$ from the southern edge of the Ubaid area in Mesopotamia and may be part of an undiscovered complex of sites that linked Mesopotamia and the Gulf. 


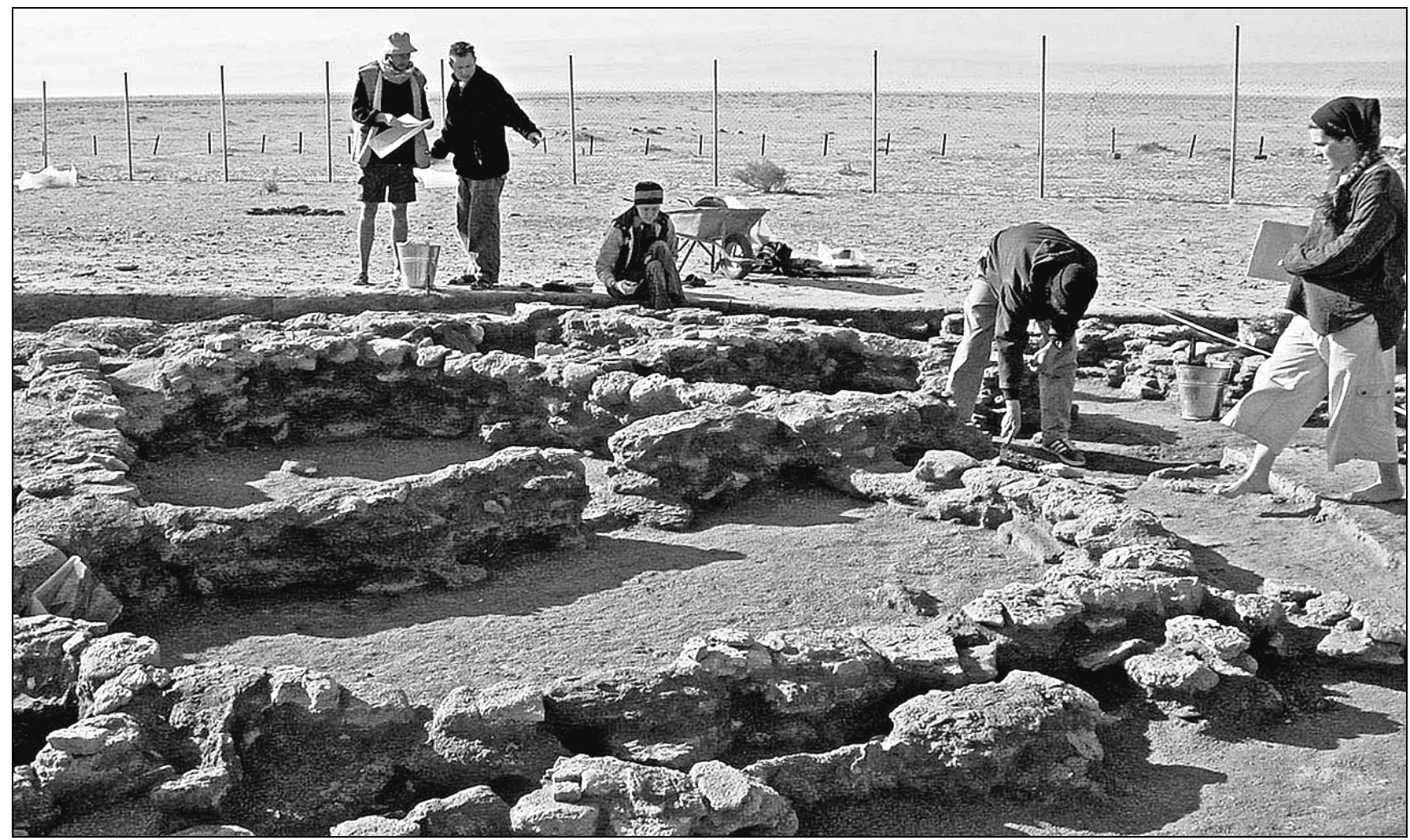

Figure 2 The Neolithic site of H3, showing chambers within one of the stone-built structures.

subsequently added to or subdivided. When the stone structures appear in the archaeological record of the site, Ubaid pottery becomes common, and personal ornaments typical of Ubaid Mesopotamia begin to occur. However, the stone-tool technology and shell jewellery found at the site remain typical of the Arabian Neolithic. The bitumen fragments from boats are associated with this occupation phase, as is the boat model.

While these changes took place, subsistence activities continued, including herding, hunting, and especially fishing and shell gathering. A few date stones recovered during the excavation imply that food was also brought from elsewhere, as this part of Kuwait is unlikely to have supported wild or cultivated date palms. Other activities at the site included the large-scale manufacture of shell jewellery, principally small, simple disc-shape beads.

The cellular stone buildings have no parallel in Mesopotamia, and currently they appear to be unique. A stone structure found at Shagra (Fig. 1), a Neolithic site in Qatar lacking Ubaid pottery, somewhat resembles them. ${ }^{9}$ Similar buildings may be buried at the major Saudi sites of this period, but these have been only partially excavated by means of narrow test pits, and no such buildings have been found.

\section{The bitumen finds}

So far, nearly 80 fragments of bitumen have been recorded from the site of H3. Of these, 22 are large enough to be informative (mainly 5-10 $\mathrm{cm}$ across and $2-3 \mathrm{~cm}$ thick).
Most consist of slabs with parallel reed impressions on one side, and barnacles adhering to the other (Fig. 3). Reed impressions and barnacles are never found on the same side. The barnacles are mature, indicating that they were submerged in sea water for several months. We believe that the bitumen once coated the hulls of seagoing vessels made of reed bundles. It acted as a waterproof envelope and also deterred the growth of weed and other marine organisms.

Four of the bitumen fragments bear impressions of string or rope on the inside. These marks are left by the binding used to tie the reeds into bundles and to lash the bundles together to form the hull. Some of the fragments are only about $1 \mathrm{~cm}$ thick. The bitumen may have been thin over much of the vessel, but the thicker pieces survived better and make up the bulk of our sample. Many of the pieces had been lost or discarded around the site, and were found in the corners of rooms or in windblown sand outside the buildings. However, some had been deliberately stored. The material was probably stripped off old or damaged boats and re-used for repairs or for the building of a new vessel. Both the coating of the reed boats with bitumen and its stripping off are mentioned in Mesopotamian Bronze Age texts, and the practice continued almost to the present day in the marshes of southern Iraq. ${ }^{10}$

The fragments of bitumen from $\mathrm{H} 3$ are very similar to Bronze Age finds from the coastal site of Ras al-jinz in Oman. ${ }^{11}$ The latter are some 3000 years younger, and the
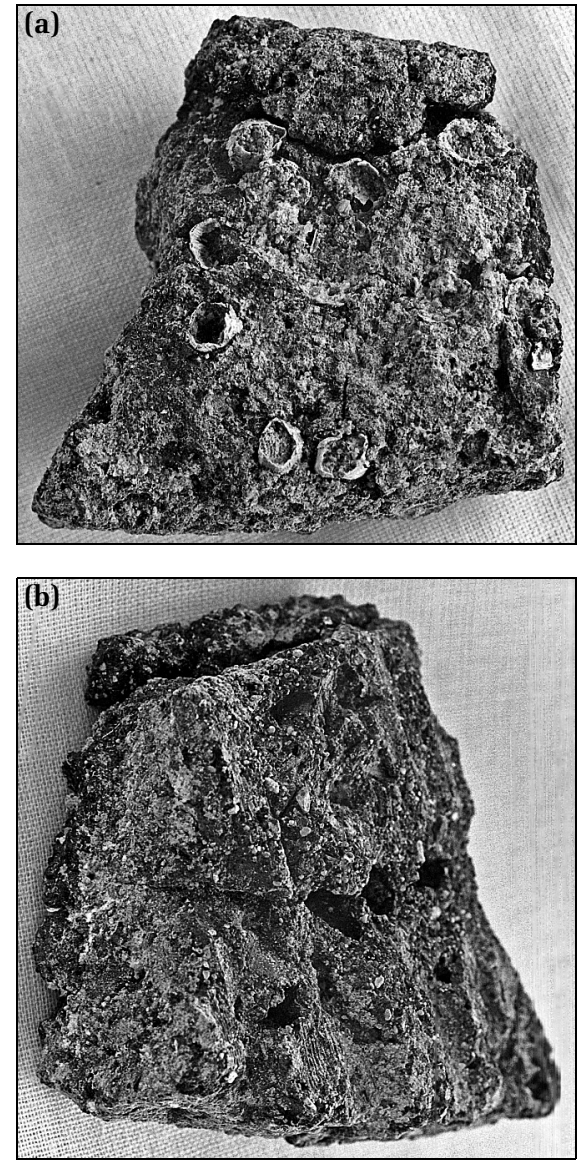

Figure 3 A slab of bitumen found at the H3 site: (a) the outer side with barnacles adhering to it; (b) the inner side showing parallel impressions of reeds. 


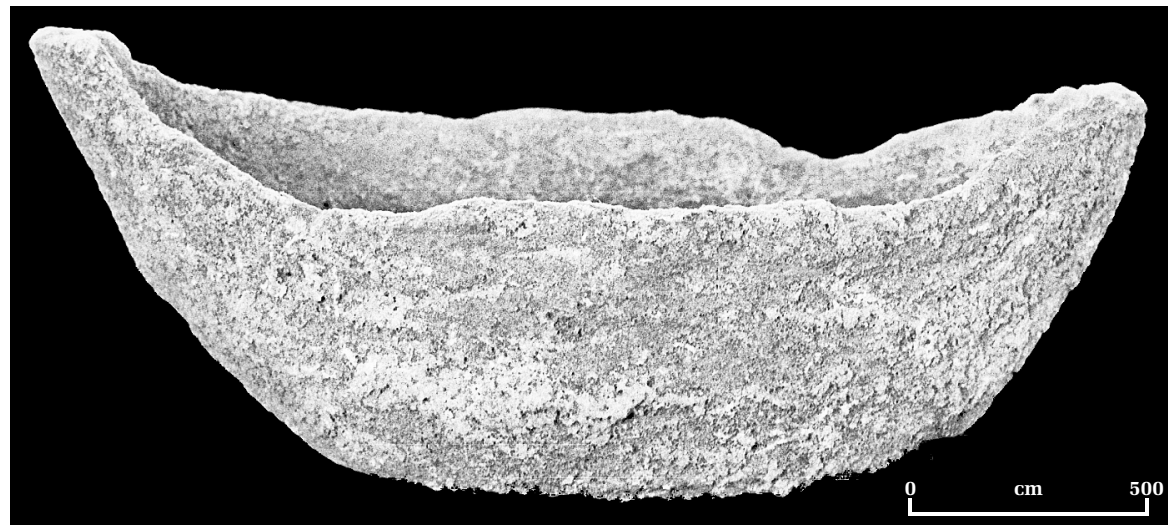

Figure 4 The clay model of a boat found in one of the chamber structures at the H3 site. It is currently undergoing conservation treatment to remove the encrusted salts, and features that indicate reed-bundle construction are beginning to be revealed.

pieces are better preserved, more abundant and larger, but the similarity is clear. Like the pieces from H3, they have reed impressions on one side and barnacles on the other. Furthermore, an important feature of the bitumen from both sites is that it is not pure, but had been deliberately mixed with coarse chopped vegetal matter, and other ingredients. Analysis of the material from Ras al-Jinz has shown that the bitumen was combined with chopped reeds, carbonates and possibly fish oil, to make an amalgam. ${ }^{12}$ This process changed the physical properties of the bitumen, making it adhesive, tough, flexible and light.

\section{Other boat-related finds from the site of $\mathrm{H3}$}

We should not assume that all the pieces of bitumen found at $\mathrm{H} 3$ are from reed boats. Throughout its history of use, bitumen has been employed to line baskets, plug or mend pottery vessels, and make beads and sculptures. ${ }^{13}$ But another find from $\mathrm{H} 3$, not of bitumen, strongly suggests that reedbundle vessels were known there. A small model of a boat, made of fired clay, was found in one of the chambers (Fig. 4). It was heavily impregnated with salt and is now undergoing conservation, but features on its hull that depict reed bundles are beginning to be revealed. Ceramic model boats are known from Ubaid contexts in Mesopotamia, one of which is completely coated with bitumen. ${ }^{14}$

A disc of painted pottery, fashioned from a broken bowl, was also found at $\mathrm{H} 3$ (Fig. 5). The original design on the bowl, a pattern with radiating lines meeting a scalloped edge, has been deliberately modified. The new motif resembles a boat with two masts. If the intention was indeed to depict a boat, then the two poles actually represent a single two-footed (bipod) mast - a common construction used on vessels whose frames were not strong enough to support a single mast socket. This find may help to answer the unresolved question of whether the technique of sailing was known in this early period. ${ }^{15}$

\section{Navigation in the Gulf during the Neolithic and Ubaid periods}

The new discoveries from the site of $\mathrm{H} 3$ allow us to speculate on the mechanics of trade during the sixth and fifth millennia BC. First, the question of whether boats were used during the Neolithic period has been answered positively. ${ }^{16}$ The vessels were made of reed bundles, lashed together and then coated with a bitumen amalgam - a technology that prefigures the techniques used to build trading vessels during the Bronze Age, some 3000 years later.

Secondly, it can be assumed that the reed-bundle boats were used to bring pottery from Mesopotamia. This pottery was almost certainly an item of trade in its own right. The most common forms found at H3 consist of painted bowls and (fewer) jars (Fig. 6), many of which are extremely fine and fragile, unsuitable for use as goods containers. It appears that this is also true of the pottery found at Ubaid-related sites in Saudi Arabia. It is unlikely that the ceramic ware was brought by Mesopotamian fishermen purely for their own use. The quantity and quality of material at the Arabian Gulf sites implies a true trading relationship with Mesopotamia. It is likely that Mesopotamia, the Central Gulf and the region in between, including $\mathrm{H} 3$, engaged in regular and direct trade, whereas the smaller quantities of Ubaid pottery found south of Qatar were probably distributed by more indirect means, passed on by groups in contact with the Central Gulf region.

It is unclear what was exchanged for the pottery. Pearls have been suggested, ${ }^{17}$ and a small pierced pearl was indeed found at H3. Evidence is mounting that pearls were valued as jewellery at this early date. ${ }^{18}$ Flint and other stones, such as obsidian, may also have been traded for the pottery, ${ }^{19}$ as well as shell jewellery such as that manufactured at H3. Also, perishable goods of various kinds, such as fish and hides, could have been exchanged, in either direction.

H3 appears to have played a significant

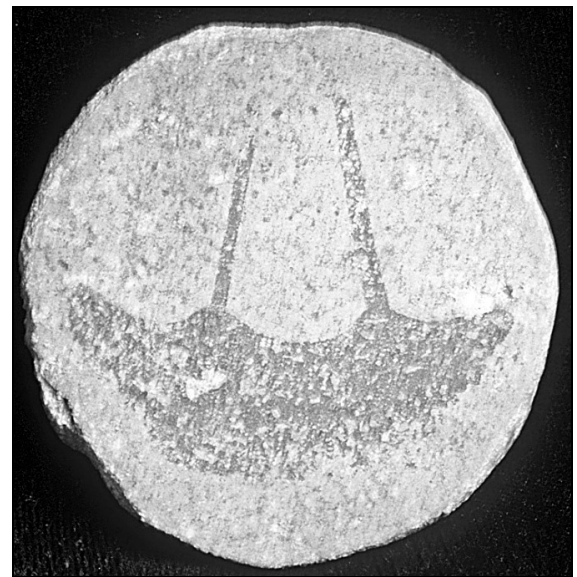

Figure 5 A painted potterydisc, $6.5 \mathrm{~cm}$ in diameter, from the $\mathrm{H} 3$ site, with a design resembling a boat with two masts.

role in the maritime trade of the region. Boats were apparently stripped of their covering of bitumen at the site. Damaged boats may have been repaired there, or they may have been built from scratch. Reed beds exist in parts of Kuwait, and surface seeps of bitumen exist. Analysis of the bitumen from $\mathrm{H} 3$ indicates that it originated from Kuwait, rather than Mesopotamia or elsewhere. This underlines the fact that we should not assume that the seaborne trade was undertaken by people from Ubaid Mesopotamia. The inhabitants of the shores of the Gulf may have played an active role in it.

We rely on circumstantial evidence to determine the routes taken by the boats. They probably hugged the coast to facilitate navigation and allow the fragile vessels to flee to shelter in bad weather. Many stops may have been made during a journey, at sites such as $\mathrm{H} 3$ and perhaps at uninhabited points along the route. The area between H3 and the Central Gulf that has not been surveyed archaeologically may contain unrecorded Ubaid-related campsites and settlements. The journey southwards from H3 would have been

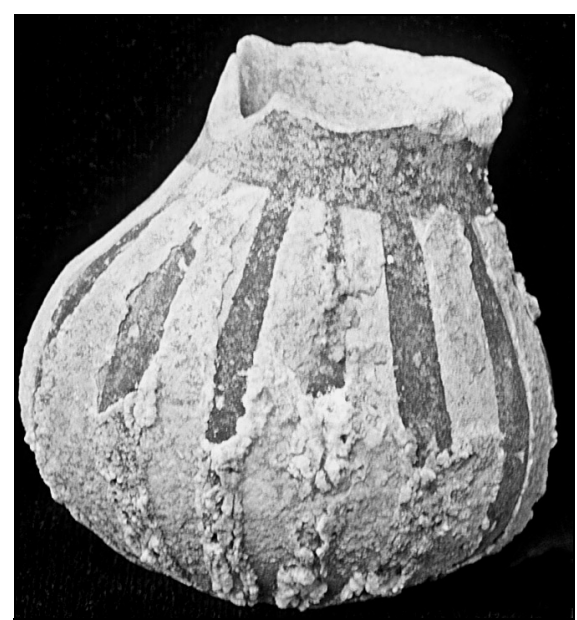

Figure 6 A painted Ubaid pottery jar from the H3 Site, partially encrusted with salts (c. $7 \mathrm{~cm}$ in diameter). 
comparatively easy, as the prevailing winds are from the north and northwest in all seasons. The journey back must have been slower and more difficult, possibly even necessitating a voyage across to the Iranian side, to catch the counter-clockwise current of the Arabian Gulf. At least one Ubaid-related site is known to exist on the Iranian coast: Halilih on the Bushehr peninsula (Fig. 1)..$^{20}$

It remains to be established whether boats journeyed in the Gulf throughout the year, or only during particular seasons. A detailed study of the fish remains found at $\mathrm{H} 3$ is beginning to suggest that occupation was not restricted to a single short visit each year, and there is evidence that people were there during more than one season. ${ }^{21}$

\section{Future research}

The site of H3 has already shed new light on the beginnings of maritime trade in the region, and it bears witness to the precocious appearance of a sophisticated technology of boat building. Many questions remain, regarding the site, its finds and the impact of the trading relationship on the societies concerned. Unfortunately, the potential for further fieldwork has been curtailed by recent political events, and the search for related sites in Kuwait and southern Iraq is hampered by the debris of recent conflicts. However, analytical work continues on the absolute chronology of $\mathrm{H} 3$ and on the stone finds, the pottery, the bitumen, the shell and the bones of fish and other animals.

\section{Notes}

1. The team is led by Harriet Crawford and myself from the UCL Institute of Archaeology. Major sponsors include Shell Kuwait, the National Council for Culture, Arts and Letters in Kuwait, the British School of Archaeology in Iraq, the New English School Kuwait, the Central Research Fund of the University of London, the Society of Arabian Studies, and the Charlotte Bonham-Carter Charitable Trust.

2. Stylistically, most of the pottery from the Gulf sites relates to the Ubaid 2/3 (= Early Ubaid 3) and Ubaid 3 periods; a few contain Ubaid 4 pottery, and one may have Ubaid 5 material (= Terminal Ubaid). Interaction between Arabia and Mesopotamia may have begun during the Ubaid 2 period, but is more likely to have begun slightly later. The Ubaid period as a whole is conventionally dated to $c$. 5500-4000 $\mathrm{BC}$, but calibrated radiocarbon dates now suggest that it may have begun as early as c. 6500 BC.

3. Petrographic and compositional analyses of Ubaid-style pottery from the Gulf have invariably shown it to be Mesopotamian in origin; see J. Oates, T. E. Davidson, D. Kamilli, H. McKerrel, "Seafaring merchants of Ur?", Iraq 51, 221-34, 1977.

4. The beginning of the Arabian Neolithic period has not been firmly established within the timespan $c .8000-6000 \mathrm{BC}$; it ended by $c .3000$ BC.
5. See pp. 232-3 in Oates et al. (1977: n. 3 above).

6. See A. H. Masry, Prehistory in northeastern Arabia: the problem of interregional interaction, (Coconut Grove, Florida: Field Research Projects, 1974).

7. For example, flanged stone and ceramic discs, sometimes thought to be lip ornaments (known as labrets). Some occur in pairs, and may have been ear ornaments. 8. Preliminary reports by Robert Carter, Harriet Crawford and others can be found in Iraq 61, 43-58, 1999, 63, 1-20, 2001, and 64, 1-13, 2002. See also R. A. Carter, "Ubaid-period boat remains from AsSabiyah: excavations by the British archaeological expedition to Kuwait", Proceedings of the Seminar for Arabian Studies 32, 13-30, 2002.

9. See pp. 99-125 in M-L. Inizan (ed.), Préhistoire à Qatar: mission archéologique française à Qatar, volume 2 (Paris: Editions Recherche sur les Civilisations, 1988).

10. See p. 64 in S. Cleuziou S. \& M. Tosi, “Ra's al-Jinz and the prehistoric coastal cultures of the Ja'alan", Journal of Oman Studies 11, 19-73, 2000; and pp. 125-8 in W. Thesiger, The marsh Arabs. (Harmondsworth: Penguin, 1976).

11. See pp. 63-6 in Cleuziou \& Tosi (2000: n. 10 above).

12. Dr Jacques Connan of the Centre National des Recherches Scientifiques in Paris, who analyzed the bitumen found at Ras al-Jinz, is currently studying the material from $\mathrm{H} 3$ and has confirmed that a similar amalgam was used there.

13. One or two bitumen items from $\mathrm{H} 3$ resemble pierced plugs, and may have had a purpose unconnected to boats.

14. See pp. 12-13 in C. Qualls, Boats of Mesopotamia before 2000 BC (Doctoral dissertation, Columbia University, New York, 1981).

15. The earliest known depiction of a sail is on an Egyptian pot of the late fourth millennium BC; see figure 6 in L. Casson, Ships and seamanship in the ancient world (Baltimore: Johns Hopkins University Press, 1995). An Ubaid-period ceramic model from Eridu may represent a boat with a mast socket, but its identification as a boat has been challenged; see T. F. Strasser, "The boat models from Eridu: sailing or spinning during the "Ubaid Period?”, Antiquity 70, 920-25, 1996.

16. Long-distance overland movement presumably also occurred; for example, whole herds of livestock, including cattle, could hardly have been transported by sea in reed-bundle boats.

17. See p. 233 in Oates et al. 1977, n. 3 above.

18. Pearls have been found at the inland Arabian Neolithic site of al-Buhais, and at an Ubaid-related site in Umm al-Quwain. Pearl-oyster middens at the major Ubaidrelated Central Gulf site of Khursaniyah may represent debris from pearl fishing.

19. Obsidian from $\mathrm{H} 3$ has been analyzed and found to have originated in western Arabia, so Arabian obsidian may have been traded for Ubaid pottery.

20. See J. Oates, "Ubaid Mesopotamia reconsidered", in The hilly flanks and beyond: essays in the prehistory of southwestern Asia presented to Robert I. Braidwood, T. C. Young, P. E. L. Smith, P. Mortensen (eds), 251-81 (Chicago: University of Chi- cago Press, Studies in Ancient Oriental Civilization no. 36, University of Chicago, 1983).

21. The fish bones and other animal remains are being studied by Dr Mark Beech of the University of York. Part of his research involves sectioning otoliths (fish ear bones), which grow in bands annually. It is therefore sometimes possible to infer the season in which the fish were caught. So far, it appears that fish are present at the site that were caught in summer, autumn and early winter. 